\title{
Variability in brood size and female length of Euphausia pacifica among three populations in the North Pacific
}

\author{
Jaime Gómez-Gutiérrez ${ }^{1,4, *}$, Leah R. Feinberg ${ }^{2}$, Tracy Shaw ${ }^{2}$, William T. Peterson ${ }^{3}$ \\ ${ }^{1}$ College of Oceanic and Atmospheric Sciences, Oregon State University, 104 Ocean Administration Building, Corvallis, \\ Oregon 97331-5503, USA \\ ${ }^{2}$ CIMRS, and ${ }^{3}$ NOAA/NMFS, Hatfield Marine Science Center, 2030 S Marine Science Drive, Newport, Oregon 97365, USA \\ ${ }^{4}$ Present address: Centro Interdisciplinario de Ciencias Marinas, Instituto Politécnico Nacional, Departamento de Plancton y \\ Ecología Marina, AP 592, CP 23096, La Paz, Baja California Sur, Mexico
}

\begin{abstract}
We compared brood sizes among adult female Euphausia pacifica Hansen, 1911 from 3 populations in the North Pacific: Puget Sound, Washington, USA; Toyama Bay, Japan; and the Oregon coast, USA. Additionally, we used multiple linear regression models to compare the interspecific brood size as a function of female length and location. The females from Oregon attained larger brood sizes (maximum 600 eggs brood ${ }^{-1}$, mean 152 eggs brood $^{-1}$ ) and were longer (mean length $20.1 \mathrm{~mm}$ ) than females from the other 2 regions (means: 96 eggs brood ${ }^{-1}$ and $15.9 \mathrm{~mm}, 113$ eggs brood $^{-1}$ and $18.5 \mathrm{~mm}$ for Puget Sound and Toyama Bay, respectively). The brood size for females from the 3 populations increased with size, reaching a maximum when females attained lengths ranging from 19 to $22 \mathrm{~mm}$. The brood size decreased substantially for larger individuals. When the relationship between brood size and length was corrected for differences in female length, the median brood sizes were statistically indistinguishable among the 3 regions, indicating an inherent reproductive potential probably associated with the carapace volume available for the gonads for a given female length.
\end{abstract}

KEY WORDS: Euphausia pacifica $\cdot$ Intraspecific scaling $\cdot$ Brood size $\cdot$ Reproductive effort $\cdot$ North Pacific Resale or republication not permitted without written consent of the publisher

\section{INTRODUCTION}

Euphausia pacifica Hansen, 1911 is distributed widely within the subarctic and transition zones of the North Pacific and is the only North Pacific Euphausia species living at northern temperate latitudes (Johnson 1956, Brinton 1962, Brinton et al. 2000). It occurs from the warm eastern coast of Korea, and from the Yellow Sea, East China Sea and the Japan/East Sea, into the cool Oyashio Current off Sanriku Japan (Chae et al. 2005, Wang et al. 2005, Xu \& Chen 2005), and northward and eastward to the Gulf of Alaska and southward into the California Current System where, during cold years, it can extend its distribution further south to the tip of the Baja California peninsula (Brinton 1962, Gómez-Gutiérrez et al. 2005). This species is also present in the southern parts of the Sea of Okhotsk and the Bering Sea (Batten et al. 2005, Brodeur \& Yamamura 2005) (Fig. 1).

Euphausia pacifica from different locations seems to have varying tolerances to changes in temperature and salinity, suggesting significant regional differences among populations (Reagan 1968, Gilfillan 1972). Given its broad distribution over regions with very different seasonal production cycles, we wondered if life history characteristics of E. pacifica were flexible enough to show differences in reproductive activity (spawning duration and spawning season, brood size, 


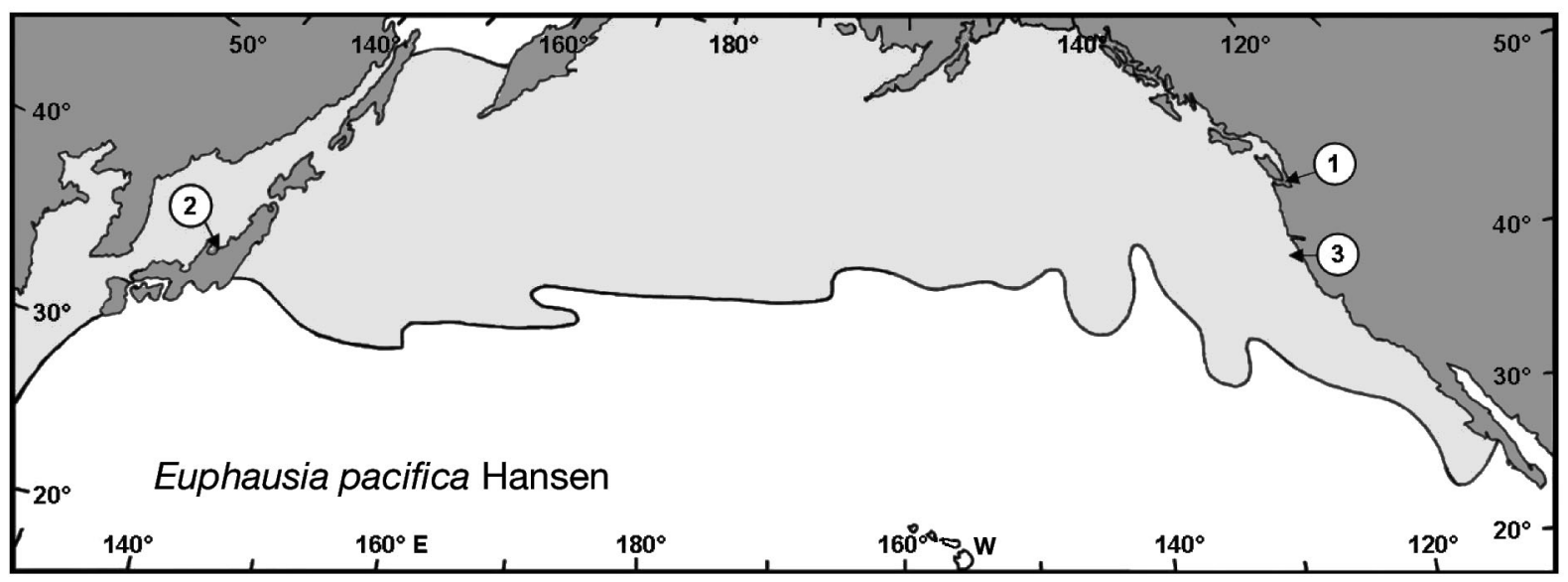

Fig. 1. Euphausia pacifica. Geographical distribution of the euphausiid (light gray), showing the locations of brood size studies: (1) Puget Sound, WA, USA, during 1976 and 1977 (Ross et al. 1982); (2) Toyama Bay, Japan, March and April 1992 (Iguchi \& Ikeda 1994); (3) Oregon coast population, USA, 1999 to 2004 (this study). Distribution range along the eastern coast of Korea, southern part of the Yellow Sea, and in the shelf areas of the China Sea, was updated from Brinton (1962) and Brinton et al. (2000) using recent distribution records (Batten et al. 2005, Chae et al. 2005, Wang et al. 2005, Xu \& Chen 2005)

and/or perhaps interbrood period). Moreover, if there were large differences in brood size for example, we should be able to detect them in populations from contrasting regions such as oceanic waters, continental shelf waters and protected inland waters.

We know that there are differences in spawning duration and spawning season for several populations of Euphausia pacifica (reviewed by Ross \& Quetin 2000). In higher latitudes ( 49 to $51^{\circ} \mathrm{N}$ ) of the eastern North Pacific in the Strait of Georgia (British Columbia), spawning is intense from May to June and less so from July to September. In Puget Sound and Dabob Bay, Washington populations $\left(48^{\circ} \mathrm{N}\right)$, high intensity spawning occurs between March and mid-May and continues at lower intensity until September (Ross et al. 1982, Bollens et al. 1992). In the Japan/East Sea (35 to $37^{\circ} \mathrm{N}$ ), spawning is restricted to the period March to May (Ponomareva 1963, Iguchi et al. 1993). Spawning occurs year-round in the Oyashio Current off the Sanriku region of Japan and off central and southern California $\left(35\right.$ to $\left.37^{\circ} \mathrm{N}\right)$, but the most intense spawning activity is between February and August (Brinton 1976, Iguchi et al. 1993, Iguchi \& Ikeda 1994, 1999, Taki 2004, Dorman et al. 2005). Off the Oregon coast $\left(45^{\circ} \mathrm{N}\right)$, Smiles \& Pearcy (1971) deduced from larval abundance that intense spawning occurs in the fall; however, recent observations indicate that spawning starts as early as February and extends through October (Feinberg \& Peterson 2003, Gómez-Gutiérrez 2003, Gómez-Gutiérrez et al. 2005).

These differences in spawning intensity and spawning season among regions motivated us to compare the geographical differences in brood size of Euphausia pacifica. Unfortunately, no other reproductive index (interbrood period, egg volume/energy content) is available for more than 2 E. pacifica populations, making brood size the only useful reproductive proxy for quantitative comparative purposes. The available data sets are quite limited and only include observations made on individuals from Puget Sound (PS), WA, USA (Ross et al. 1982), Toyama Bay (TB), Japan (Iguchi \& Ikeda 1994, 1999), and the Oregon coast (OC), USA (Gómez-Gutiérrez 2003). We used a meta-analysis of brood size (eggs brood ${ }^{-1}$ ) and the female total length $(\mathrm{mm})$ to examine scaling of brood size among these $3 \mathrm{E}$. pacifica populations in the North Pacific. Theoretically, the scaling of brood size among females of varying length within the same species should have a substantially lower slope than interspecific scaling among species (Mauchline 1988, Gómez-Gutiérrez 2003). However, except for the studies by Reagan (1968) and Gilfillan (1972) on temperature and salinity tolerance, no quantitative intraspecific comparison of any vital rate has been attempted with euphausiids. Our aim was to test the hypothesis that the brood sizes of E. pacifica females from 3 different North Pacific populations differ significantly after accounting for female size. Our study may offer a new understanding of reproductive adaptation of E. pacifica to local conditions.

\section{MATERIALS AND METHODS}

Euphausia pacifica brood size estimation. We used both published (Ross et al. 1982, Iguchi \& Ikeda 1994) and our own data on brood size and female length measured from shipboard and laboratory incubations from 3 regions of the North Pacific (Table 1). In PS, 
Table 1. Summary of the methodology for sampling and incubations under laboratory conditions of females of Euphausia pacifica to estimate brood size (eggs female ${ }^{-1}$ ) among 3 populations in the North Pacific: Puget Sound, WA, USA (Ross et al. 1982), Toyama Bay, Japan (Iguchi \& Ikeda 1994) and along the Oregon Coast, USA (1999 to 2004)

\begin{tabular}{|c|c|c|c|}
\hline Characteristic & Puget Sound, USA & Toyama Bay, Japan & Oregon coast, USA \\
\hline Oceanographic cruises & 5 & 2 & 29 \\
\hline Period of sampling & $\begin{array}{l}\text { April to June } 1976-1977 \text {, } \\
\text { sampled every } 2 \mathrm{wk}\end{array}$ & March and April 1992 & $\begin{array}{l}\text { Sampled seasonally and every } \\
2 \text { wk on the Newport Hydro- } \\
\text { graphic line from } 1999 \text { to } 2004 \\
\left(44.18^{\circ} \mathrm{N}, 124^{\circ} 10^{\prime} \mathrm{W}\right) \text {. Ripe } \\
\text { females were found only } \\
\text { between March and Septembe }\end{array}$ \\
\hline Location & $\begin{array}{l}48.6^{\circ} \mathrm{N}, 122.22^{\circ} \mathrm{N} \\
\text { shallow inlet waters } \\
\text { at } \sim 80 \mathrm{~m} \text { depth }\end{array}$ & $\begin{array}{l}37.0^{\circ} \mathrm{N}, 137.14^{\circ} \mathrm{E} \\
\text { oceanic waters } \\
1000 \mathrm{~m} \text { depth }\end{array}$ & $\begin{array}{l}42.0 \text { to } 44.65^{\circ} \mathrm{N}, 124.3 \text { to } \\
126.2^{\circ} \mathrm{W} \text {, inshore }(<200 \mathrm{~m}) \text { and } \\
\text { offshore }(>200 \mathrm{~m}) \text { environment }\end{array}$ \\
\hline Sampling gear & $\begin{array}{l}1 \mathrm{~m} \text { net or NIO net, both } \\
571 \mu \mathrm{m} \text { mesh net }\end{array}$ & $\begin{array}{l}1.83 \mathrm{~m}^{2} \text { Isaacs-Kidd Mid Water } \\
\text { Trawl (IKMT) and } 1.3 \mathrm{~m} \text { net } \\
\text { diameter } 500 \mu \mathrm{m} \text { mesh net }\end{array}$ & $\begin{array}{l}1 \text { m diameter, } 300 \mu \mathrm{m} \text { net with } \\
0.7 \text { length } \times 0.25 \text { diameter } \\
\text { closed cod end (live net), } 1 \mathrm{~m}^{2} \\
\text { MOCNESS, and } 0.6 \mathrm{~m} \text { diame- } \\
\text { ter Bongo net } 333 \mu \mathrm{m} \text { mesh net }\end{array}$ \\
\hline Incubation method & $\begin{array}{l}\text { Bottles } 11,8 \text { and } 12^{\circ} \mathrm{C} \text {, } \\
\text { fed with suspension of } \\
\text { cultured diatoms }\end{array}$ & $\begin{array}{l}\text { Bottles } 0.91,11^{\circ} \mathrm{C} \text {, } \\
\text { fed with natural seston }\end{array}$ & $\begin{array}{l}\text { Bottles } 11,10^{\circ} \mathrm{C} \text {, fed with } \\
\text { natural seston }\end{array}$ \\
\hline Incubation time & $24 \mathrm{~h}$, inspected every $6 \mathrm{~h}$ & $24 \mathrm{~h}$, inspected daily & $\leq 48 \mathrm{~h}$, inspected every $12 \mathrm{~h}$ \\
\hline Female length measurement & $\begin{array}{l}\text { Total length calculated } \\
\text { from dry weight data }\end{array}$ & Total length & Total length \\
\hline
\end{tabular}

euphausiids were collected near Port Susan $\left(48.6^{\circ} \mathrm{N}\right.$, $122.22^{\circ} \mathrm{W}$; station depths of approximately $\left.80 \mathrm{~m}\right)$, representing a shallow, estuarine environment (Ross et al. 1982). In Japan, euphausiids were collected in TB, a large deep bay (>1000 m) with a wide mouth at its connection with the Japan Sea. The sampling station was located at $37.0^{\circ} \mathrm{N}, 137.14^{\circ} \mathrm{E}$ near the $1000 \mathrm{~m}$ isobath, thus representing an oceanic environment (Iguchi et al. 1993, Iguchi \& Ikeda 1994). The OC sampling area included continental shelf, shelf-break and offshore waters (42 to $44.65^{\circ} \mathrm{N}, 124.3$ to $126.2^{\circ} \mathrm{W}$ ) and ripe euphausiids were collected between April and September 1999 to 2004. The sampling area includes a significant inshore-offshore habitat gradient in both phytoplankton and copepod biomass (high biomass inshore, low biomass offshore) (Peterson et al. 2002, Lamb \& Peterson 2005). Thus, the area was divided into inshore $(<200 \mathrm{~m}$ depth) and offshore $(>200 \mathrm{~m}$ depth) regions. The 4 data sets thus include a gradient of Euphausia pacifica habitats from shallow enclosed estuary waters (PS), to a deep bay (TB), continental shelf waters (OC, inshore) and open-ocean conditions (OC, offshore), and include E. pacifica populations from both the western and eastern Pacific.

Euphausia pacifica females from the OC region were collected at night between July 1999 and September 2004 (29 oceanographic cruises) using a variety of plankton nets (Table 1). Contents of the cod ends of these nets were poured into a cooler with $20 \mathrm{l}$ of sur- face seawater. Mature females with purple ovaries were removed from the catch and placed individually into 11 transparent polypropylene bottles filled with $200 \mu \mathrm{m}$ filtered seawater. At $12 \mathrm{~h}$ intervals for a $48 \mathrm{~h}$ period, each bottle was examined and, if eggs were present, the female was removed, the water was sieved to remove the eggs (which were then preserved with $5 \%$ formalin) and the female was returned to the bottle. Eggs were counted with the aid of a binocular dissecting microscope. Brood size was calculated as the cumulative number of eggs produced during the $48 \mathrm{~h}$ period. At the end of the experiment, female total length was measured from the posterior edge of the eye to the tip of the telson. All uses of the term length (L) in this paper refer to total length. E. pacifica brood size data from literature were used for PS and TB regions. There were some slight differences in the methods of measuring brood size among studies (Table 1).

For the PS region, the brood size and female lengths were calculated directly from data presented in Fig. 2 of Ross et al. (1982) by transforming female dry weight (DW), expressed in $\mathrm{mg}$, to female total length (mm) using their equation: $\mathrm{DW}=1.45 \mathrm{~L}-18.06\left(\mathrm{r}^{2}=0.943\right.$, $\mathrm{n}=41$ ). For the TB region, the original brood size and female total length data set was kindly provided by Naoki Iguchi (pers. comm.; from Iguchi \& Ikeda 1994). For some comparisons of length and brood size among populations we used the same length range intervals 
as Ross et al. (1982) as follows: $<17 \mathrm{~mm}, 17$ to $19 \mathrm{~mm}$ and $>19 \mathrm{~mm}$.

Analysis of covariance of Euphausia pacifica brood size. To test for differences in brood size as a function of female size among Euphausia pacifica populations in the North Pacific, we conducted a meta-analysis of covariance using multiple linear regression models to compare the relationship between brood size (eggs female $^{-1}$ ) and female length ( $\mathrm{mm}$ ) among 3 populations following methods described by Ramsey \& Shafer (1996). Logarithm transformation was carried out to linearize the data and reduce variability. The effect of the brood size (explanatory variable) is the mean response that is associated with a one-unit increase in this reproductive index while holding all other variables constant. In this case, the constant variables are female length and population region.

We set the intercept of multiple linear regression models as the minimum female length at first maturity recorded in any of the 3 populations $(\sim 12 \mathrm{~mm}$, as observed in the present analysis for females with young oocytes stage I). We tested a parallel line full model (Log BS $=\beta_{0}+\beta_{1} \log \mathrm{L}-12 \mathrm{~mm}+\beta_{2}$ Toyama + $\beta_{3}$ Oregon), and a reduced model (Log $\mathrm{BS}=\beta_{0}+$ $\beta_{1} \log \mathrm{L}-12 \mathrm{~mm}$ ) to test for differences in the intercepts for the association of brood size and female length by regions (see Table 3) where Log BS is the logarithm of the brood size (eggs female ${ }^{-1}$ ), LogL $-12 \mathrm{~mm}$ is the logarithm of the female length after subtracting the length at first maturity and Toyama and Oregon are indicator variables for each region. The PS population was treated here as the reference level. The intercept for PS is the coefficient $\beta_{0}$; for TB it is $\beta_{0}+\beta_{2}$ and for OC it is $\beta_{0}+\beta_{3}$. Thus, if the last 2 are equal to zero, the intercepts for all the 3 populations are statistically the same.

Additionally, we fitted a non-parallel full model, incorporating different intercepts and slopes expressed as interaction terms, to test that the regression lines are indeed parallel. The separate full model is $\log B S=\beta_{0}+\beta_{1} \log \mathrm{L}-12 \mathrm{~mm}+\beta_{2}$ Toyama $+\beta_{3}$ Oregon $+\beta_{4}(\log \mathrm{L}-12 \mathrm{~mm} \times$ Toyama $)+\beta_{5}(\log \mathrm{L}-12 \mathrm{~mm} \times$ Oregon). The reduced model was $\operatorname{LogBS}=\beta_{0}+\beta_{1} \log \mathrm{L}-$ $12 \mathrm{~mm}+\beta_{2}$ Toyama $+\beta_{3}$ Oregon (see Table 3 ).

Interspecific comparison of egg size as a function of total length in euphausiids. Brood size in broadcast spawning euphausiids has been estimated for only a few species (reviewed in Ross \& Quetin 2000), but average egg sizes have been reported more frequently (Mauchline 1988, Gómez-Gutiérrez 2003). Assuming that the brood size has a direct association with the length of each euphausiid species (and thus with the volume of the ovary), then the egg diameter (ED) could be a proxy for relative female brood size. To provide a general perspective about the interspecific variability of egg diameter and the relationship between female size and reproductive investment (expressed as egg size) among the species of the Order Euphausiacea, we compared egg diameters (Mauchline 1988, Brinton et al. 2000, Gómez-Gutiérrez 2003) and the adult maximum total length (MTL) (Baker et al. 1990) for broadcast-spawning euphausiids around the world.

\section{RESULTS}

For the 3 Euphausia pacifica populations, there was a relatively similar increase in brood size as a function of body length up to $23 \mathrm{~mm}$, with slopes ranging between 10.0 for PS and 17.7 for TB (Fig. 2A-D). For larger females, brood size tended to decrease with body length (Fig. 2C-D, black circles). The average brood size was marginally smaller for PS (96 eggs female $^{-1}$ ) than for TB (113 eggs female $\left.{ }^{-1}\right)(t$-test, $\mathrm{p}<$ 0.0514); however, the average brood sizes of both regions were significantly smaller than for the OC population (152 eggs female $\left.{ }^{-1}\right)$ for all size classes ( $t$-test, $\mathrm{p}<0.0002$ ) (Table 2). However, the average brood sizes of females in inshore $(<200 \mathrm{~m})$ and offshore $(>200 \mathrm{~m})$ regions of the OC were statistically indistinguishable (161 vs. 147 eggs female ${ }^{-1}$, respectively; $t$-test, $\mathrm{p}>0.099)$. Females were significantly smaller in PS (mean L $=15.9 \mathrm{~mm}$ ) than in TB (mean $\mathrm{L}=18.5 \mathrm{~mm}$ ) $(t$-test, $\mathrm{p}<0.0001)$. On average, females in TB were also significantly smaller than those at OC (mean L = $20.1 \mathrm{~mm}$ for whole data set; $t$-test, $\mathrm{p}<0.0001)$. In the OC region, the average length of females recorded inshore $(<200 \mathrm{~m})$ was significantly longer than for offshore females $(>200 \mathrm{~m})(t$-test, $\mathrm{p}<0.0007)$ (Table 2).

When females were separated into 3 size classes, $<17 \mathrm{~mm}, 17$ to $19 \mathrm{~mm}$ and $>19 \mathrm{~mm}$, the brood sizes of females were statistically indistinguishable among any of the 3 locations ( $t$-test, $\mathrm{p}>0.106$ ) except for PS where the females between 17 and $19 \mathrm{~mm}$ produced smaller brood sizes than the corresponding females in the OC region $(t$-test, $\mathrm{p}<0.009)$. Also, OC-inshore females $<17 \mathrm{~mm}$ produced more eggs than the same size class in the OC-offshore region $(t$-test, $\mathrm{p}<0.008)$. Analysis of female size indicated that those from TB and OC were statistically larger than females from PS within the $<17 \mathrm{~mm}$ and 17 to $19 \mathrm{~mm}$ length ranges ( $t$-test, $\mathrm{p}<$ 0.029). Females from OC were statistically larger than those from the other 2 regions for the $>19 \mathrm{~mm}$ size range ( $t$-test, $\mathrm{p}<0.003)$.

\section{Analysis of covariance of Euphausia pacifica brood size}

The multiple linear regression models to test whether median brood sizes (intercepts) were signifi- 


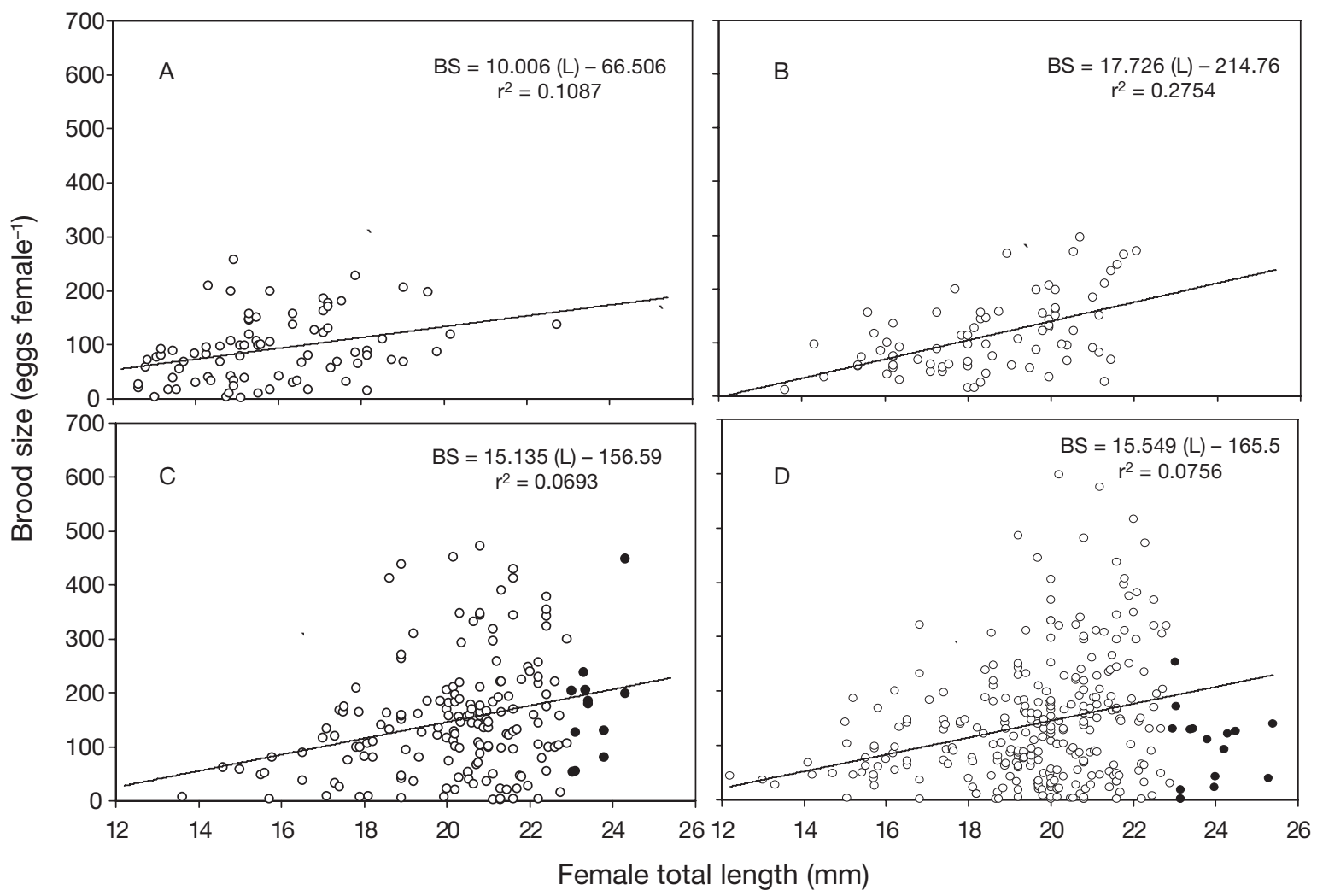

Fig. 2. Euphausia pacifica. Simple linear regression of the brood size (eggs female ${ }^{-1}$ ) as a function of the female total length (mm) among 3 populations in the North Pacific: (A) Puget Sound (Ross et al. 1982); (B) Toyama Bay (Iguchi \& Ikeda 1994), and (C,D) the Oregon coast divided into (C) inshore $(<200 \mathrm{~m}$ depth) and (D) offshore ( $200 \mathrm{~m}$ depth) stations. For comparative purposes

females larger than $23 \mathrm{~mm}$ in the Oregon coast population (•) were excluded from the simple linear regression models

cantly different among regions indicate that, independently of region and environmental conditions, females of similar length produced the same number of eggs. Thus, there were no regional differences in brood size, and the variability is well explained by female length $(\mathrm{p}>0.05$; extra-sums-squares $F$-test $=$ 0.537). The $95 \%$ confidence interval for the brood size multiplicative effect, accounting for length, indicates that TB females produce between 0.70 and 1.16 times less or more eggs than PS females and that OC females produce between 0.80 and 1.24 times less or more eggs than PS females (Table 3).

After establishing that the median brood sizes (intercepts) were not statistically different, we employed a multiple linear regression model to test if there were statistical differences in the slopes among regions. This

Table 2. Euphausia pacifica. Comparison of the average female total length $(\mathrm{mm})$ and brood size (eggs female ${ }^{-1}$ ) among 3 populations of euphausiids in the North Pacific: Puget Sound, WA, USA, (Ross et al. 1982), Toyama Bay, Japan (Iguchi \& Ikeda 1994) and along the Oregon coast, USA (1999 to 2004). STD: standard deviations; $\mathrm{S}_{\mathrm{x}}$ : standard error (shown in parentheses). The total length and brood size data from the Oregon Coast region was divided into inshore $(<200 \mathrm{~m}$ depth) and offshore ( $>200 \mathrm{~m}$ depth) regions. Females that produced brood sizes of $<10$ eggs female ${ }^{-1}$ were removed from the statistical analysis $(\mathrm{n}=37$ females; 4 from Puget Sound, 33 from the Oregon coast population)

\begin{tabular}{|c|c|c|c|c|c|c|c|}
\hline \multirow{2}{*}{ North Pacific region } & \multirow[t]{2}{*}{$\mathrm{N}$} & \multicolumn{3}{|c|}{ Total length $(\mathrm{mm})$} & \multicolumn{3}{|c|}{- Brood size (eggs female ${ }^{-1}$ ) } \\
\hline & & Average & $\operatorname{STD}\left(\mathrm{S}_{\mathrm{x}}\right)$ & Range & Average & $\operatorname{STD}\left(\mathrm{S}_{\mathrm{x}}\right)$ & Range \\
\hline Puget Sound, WA, USA & 79 & 15.9 & $2.00(0.22)$ & $12.6-22.7$ & 96.0 & $58.27(6.56)$ & $11-258$ \\
\hline Toyama Bay, Japan & 77 & 18.5 & $2.04(0.23)$ & $13.6-22.1$ & 112.8 & $69.04(7.87)$ & $12-296$ \\
\hline Oregon coast, USA & 477 & 20.1 & $2.11(0.10)$ & $12.2-25.4$ & 152.4 & $107.18(5.09)$ & $11-599$ \\
\hline Oregon coast, USA, inshore & 177 & 20.4 & $1.98(0.15)$ & $13.6-24.3$ & 160.7 & $102.38(7.97)$ & $15-473$ \\
\hline Oregon coast, USA, offshore & 300 & 19.9 & $2.18(0.13)$ & $12.2-25.4$ & 147.4 & $109.8(6.57)$ & $11-599$ \\
\hline Full data set & 600 & 19.3 & $2.53(0.10)$ & $12.2-25.4$ & 139.9 & $100.03(4.08)$ & $11-599$ \\
\hline
\end{tabular}


Table 3. ANCOVA using an inferential-multiple linear regression model to compare the minimum brood sizes per population (intercepts) and rate of increase of brood size (slopes) of the association between brood size (BS, eggs female ${ }^{-1}$ ) and female total length minus the total length of females at first maturity ( $\mathrm{L}=12 \mathrm{~mm}$ ) of Euphausia pacifica among 3 populations in the North Pacific: Puget Sound, WA, USA (Ross et al. 1982), Toyama Bay, Japan (Iguchi \& Ikeda 1994) and along the Oregon coast, USA (this study). All of the coefficients and the $95 \%$ confidence interval of the coefficients are expressed as $\log _{10}$

\begin{tabular}{|c|c|c|c|c|c|c|}
\hline & Coefficients $( \pm 95 \%$ CI $)$ & Error & $t$-value & $p=(>|t|)$ & $\mathrm{r}^{2}$ & $\mathrm{df}$ \\
\hline \multicolumn{7}{|c|}{ Model to test differences between intercepts (parallel model) } \\
\hline \multicolumn{7}{|c|}{ (T) } \\
\hline Intercept $\left(\beta_{0}\right)$ & $1.486(1.346$ to 1.626$)$ & 0.071 & 20.833 & 0.000 & 0.0965 & 596 \\
\hline $\log \mathrm{L}-12 \mathrm{~mm}\left(\beta_{1}\right)$ & 5.106 (3.559 to 6.653$)$ & 0.787 & 6.484 & 0.000 & & \\
\hline Toyama $\left(\beta_{2}\right)$ & $-0.043(-0.152$ to 0.065$)$ & 0.055 & -0.781 & 0.435 & & \\
\hline Oregon $\left(\beta_{3}\right)$ & $-0.001(-0.096$ to 0.095$)$ & 0.049 & -0.015 & 0.988 & & \\
\hline \multicolumn{7}{|l|}{ Reduced model } \\
\hline Intercept $\left(\beta_{\mathrm{o}}\right)$ & $1.4722(1.336$ to 1.610$)$ & 0.070 & 21.133 & 0.000 & 0.0978 & 598 \\
\hline $\log L-12 \mathrm{~mm}\left(\beta_{1}\right)$ & $5.174(3.923$ to 6.426$)$ & 0.637 & 8.118 & 0.000 & & \\
\hline \multicolumn{7}{|c|}{ Model to test differences between intercepts and slopes (non-parallel model) } \\
\hline \multicolumn{7}{|c|}{ ( } \\
\hline Intercept $\left(\beta_{\mathrm{o}}\right)$ & $1.471(1.174$ to 1.767$)$ & 0.151 & 9.740 & 0.000 & 0.0978 & 594 \\
\hline $\log \mathrm{L}-12 \mathrm{~mm}\left(\beta_{1}\right)$ & 5.3027 (1.602 to 9.003$)$ & 1.884 & 2.814 & 0.005 & & \\
\hline Toyama $\left(\beta_{2}\right)$ & $-1.436(-3.878$ to 1.007$)$ & 1.244 & -1.154 & 0.249 & & \\
\hline Oregon $\left(\beta_{3}\right)$ & 0.378 (-1.345 to 2.102$)$ & 0.878 & 0.431 & 0.668 & & \\
\hline LogL - $12 \mathrm{~mm} \times$ Toyama $\left(\beta_{4}\right)$ & $1.097(-0.877$ to 3.072$)$ & 1.005 & 1.092 & 0.275 & & \\
\hline LogL - $12 \mathrm{~mm} \times$ Oregon $\left(\beta_{5}\right)$ & $0.297(-1.712$ to 1.118$)$ & 0.720 & -0.412 & 0.681 & & \\
\hline \multicolumn{7}{|l|}{ Reduced model } \\
\hline Intercept $\left(\beta_{\mathrm{o}}\right)$ & $1.486(1.346$ to 1.626$)$ & 0.071 & 20.833 & 0.000 & 0.0965 & 596 \\
\hline $\log L-12 \mathrm{~mm}\left(\beta_{1}\right)$ & 5.106 (3.559 to 6.653$)$ & 0.787 & 6.484 & 0.000 & & \\
\hline Toyama $\left(\beta_{2}\right)$ & $-0.043(-0.152$ to 0.065$)$ & 0.055 & -0.781 & 0.435 & & \\
\hline Oregon $\left(\beta_{3}\right)$ & $-0.001(-0.096$ to 0.095$)$ & 0.049 & -0.015 & 0.988 & & \\
\hline
\end{tabular}

analysis produced no statistical evidence that the slopes of the association between brood size among the 3 regions differed after accounting for female length ( $\mathrm{p}>0.05$; extra-sums-squares $F$-test $=1.489)$ (Table 3). Similar results were obtained when the OC population was divided into OC-inshore $(<200 \mathrm{~m})$ and OC-offshore $(>200 \mathrm{~m})$ regions (multiple regression models not shown).

To estimate the average rate of increase of brood size at intervals of female length and explore the inherent capability of Euphausia pacifica females to produce larger brood sizes as they become larger, we calculated the simple linear regression model using all the available data: $\mathrm{BS}=8.51(\mathrm{~L})+41.83\left(\mathrm{r}^{2}=0.56\right.$, $\mathrm{p}=0.0012, \mathrm{n}=600$ females) (Fig. 3). The highest variability in brood size occurred in females 19 to $22 \mathrm{~mm}$ long, Small broods $\left(<100\right.$ eggs female $\left.{ }^{-1}\right)$ could be produced by females of any size within the entire size range of mature females observed in this study, i.e. 12 to $25 \mathrm{~mm}$. Intermediate broods $(\leq 250$ eggs female $^{-1}$ ) were produced by females ranging from 14 to $18 \mathrm{~mm}$ in length. For broods $>250$ eggs female ${ }^{-1}$, the range in female length was quite large at 17 to $24 \mathrm{~mm}$ (Fig. 3). The largest females, $25 \mathrm{~mm}$, produced fewer eggs than females ranging in length from 14 to $24 \mathrm{~mm}$.

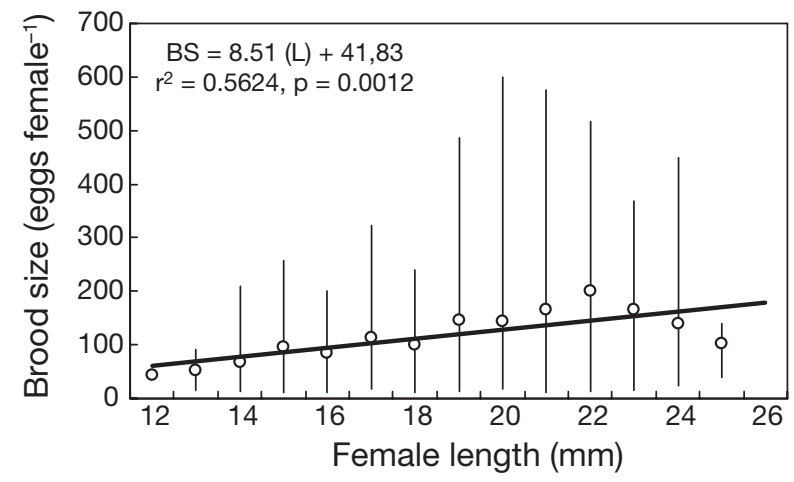

Fig. 3. Euphausia pacifica. Simple linear regression of mean brood size as a function of female length, using all available data from Toyama Bay, Puget Sound and Oregon coast populations. Vertical lines show the minimum and maximum values of brood size observed

\section{Interspecific comparison of egg size as a function of total length in euphausiids}

Our analyses indicate that there is no difference in brood size among 3 populations of Euphausia pacifica (we did not observe intraspecific variability). However, we would expect to see larger interspecific variability in brood size. Since egg diameter is the only reproduc- 
tive index commonly reported in euphausiid species, we used it for an interspecific comparison. A simple linear regression model indicates that there is a significant direct association between average ED and MTL: $\mathrm{ED}=0.1208+0.0156 \mathrm{MTL}\left(\mathrm{r}^{2}=0.8129, \mathrm{p}<0.0001\right)$. The slope of the relationship is 0.016 , meaning that there is an increase of about $0.02 \mathrm{~mm}$ in the ED per $\mathrm{mm}$ increase in the MTL of euphausiids (Fig. 4). For euphausiids of a given length, data points above the line in Fig. 4 indicate species with larger eggs than those below the line. Therefore, assuming similar body volumes, females above the line should produce fewer eggs than those below the line. We do not know if there is any relationship between egg diameter and brood size, but if larger eggs indicate smaller brood sizes, then this would suggest that epipelagic oceanic species like Thysanoessa longipes, Euphausia similis, Thysanopoda tricuspidata, and Euphausia gibboides, which have relatively large egg sizes may have proportionally smaller brood sizes than E. pacifica. The epipelagic species Euphausia diomedeae, Thysanoessa longicaudata, Thysanoessa inspinata, Nematobrachion flexipes and Meganyctiphanes norvegica seem to have egg diameters proportionally similar to E. pacifica because they are close to the regression

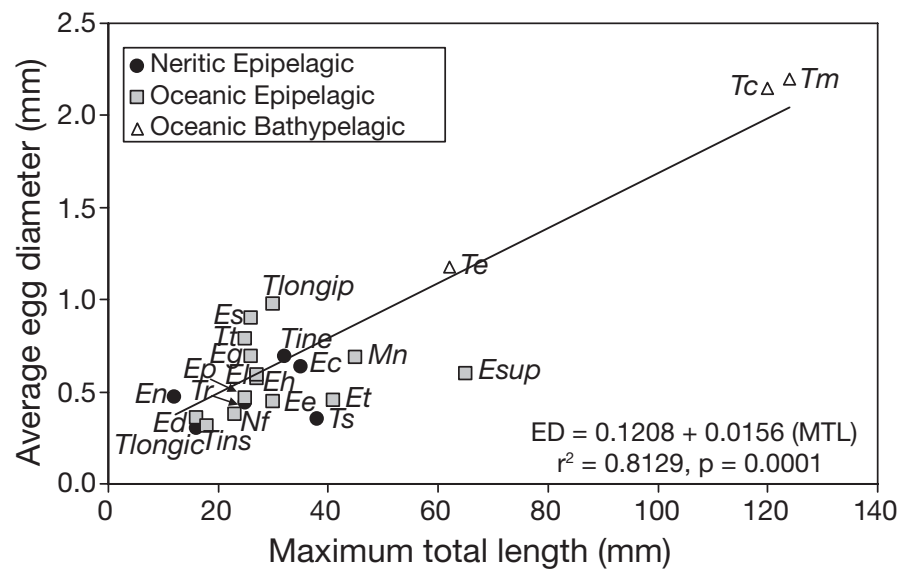

Fig. 4. Interspecific comparison of average egg diameter (ED) and maximum total length (MTL) for 23 broadcast spawning euphausiid species. Six of them are considered epipelagic neritic (Euphausia crystallorophias $[E c]$, Euphausia nana ([En], Thysanoessa inermis [Tine], Thysanoessa longicaudata [Tlongic], Thysanoessa raschi [Tr] and Thysanoessa spinifera [Ts]); 14 are considered epipelagic oceanic species (Euphausia diomideae $[E d]$, Euphausia eximia $[E e]$, Euphausia gibboides [Eg], Euphausia hanseni [Eh], Euphausia lucens [El], Euphausia pacifica $[E p]$, Euphausia similis $[E s]$, Euphausia superba [Esup], Euphausia triacantha [Et], Meganyctiphanes norvegica $[\mathrm{Mn}]$, Nematobrachion flexipes $[\mathrm{Nf}]$, Thysanoessa inspinata [Tins], Thysanoessa longipes [Tlongip], Thysanopoda tricuspidata [Tt]) and 3 are bathypelagic oceanic species (Thysanopoda cornuta [Tc], Thysanopoda egreria [Te] and Thysanopoda minyops [Tm]) (Mauchline 1988, GómezGutiérrez 2003) line. The euphausiids Euphausia triacantha, Thysanoessa spinifera and Euphausia superba apparently have proportionally smaller egg size than E. pacifica, after accounting for female length. T. longipes is the species with the largest egg size proportional to its maximum adult length.

\section{DISCUSSION}

One goal of this study was to test for differences in brood size among 3 Euphausia pacifica populations living in regions with different seasonal cycles of primary productivity. We initially expected that females from the Oregon continental shelf might be more fecund than females inhabiting relatively enclosed water bodies, like PS, simply due to differences in seasonal availability of phytoplankton food for the adult euphausiids. Both PS and TB have earlier and shorter spawning seasons (March to May) compared to the populations in the $\mathrm{OC}$ upwelling zone (April to September). A relatively short period of primary production could supposedly give the euphausiids comparatively little time to feed and invest energy in reproduction. Longer spawning seasons resulting from frequent phytoplankton blooms as a result of upwelling (Feinberg \& Peterson 2003) should contribute to an increase in the maximum potential fecundity at each female body size interval, thus maximizing the overall population reproductive effort. However, what appeared to be large differences in mean brood sizes among populations could be accounted for by differences in body size: OC females were larger than those from PS or TB; thus, they produced larger broods. This suggests that euphausiids living in regions characterized by intense phytoplankton blooms over relatively short periods of time in spring are equally as likely to produce size-specific brood sizes as those living in regions with prolonged primary production cycles. The only difference between the 3 populations may be in lifetime fecundity: this life history trait should be higher for OC females because the period over which primary production occurs is longer (up to 6 mo compared to 1-2 mo in PS and TB). Fecundity is the product of brood size and interbrood period. To test the hypothesis that fecundity is different, one would need measurements of interbrood period from all 3 regions, and such measurements are lacking in most studies.

An intriguing feature of the brood size-body length relationship was that females of intermediate size (19 to $22 \mathrm{~mm}$ ) produced the greatest number of eggs (bellshaped distribution). This could be the result of a reduction in fecundity among larger (and presumably older) females. An alternate hypothesis comes from 
one of our unpublished experiments (L. R. Feinberg et al. unpubl.), in which we maintained more than 30 female Euphausia pacifica in the laboratory and checked the egg production of each individual daily for 4 to 9 mo. Each female in this experiment was in the 19 to $22 \mathrm{~mm}$ size range, and brood sizes ranged from a few eggs up to a maximum of 800 eggs female ${ }^{-1}$. We found that 41 of 284 broods (14\%) produced in the laboratory contained $>250$ eggs female ${ }^{-1}$. For the shipboard incubation data reported in the present study, we found a similar proportion: 73 broods out of 600 $(12 \%)$ produced in our OC incubations contained $>250$ eggs female ${ }^{-1}$. Thus, the range observed in our OC incubations is matched by our unpublished laboratory observations, suggesting that any apparent 'bellshaped' relationship may be due solely to natural variability within individual females in the 19 to $22 \mathrm{~mm}$ size class, and that among any given set of females within this size class one can expect that about one in 7 broods from the same female will contain $>250$ eggs. Therefore, a population of euphausiids does not necessarily contain females with anomalously high fecundity, because all females seem capable of producing large or small broods.

Lack of brood sizes $>250$ eggs female ${ }^{-1}$ for very large females (>23 mm) may simply be due to the fact that we do not often catch large females, perhaps reflecting their relatively reduced abundance caused by age- or size-dependent mortality. For example, a recently discovered parasitoid apostome ciliate species (Collinia oregonensis) infects Euphausia pacifica and can cause mass mortality events (Gómez-Gutiérrez et al. 2003). These ciliates tend to infect mostly larger females, so as to maximize the ciliate reproductive process from the biomass of the host (Gómez-Gutiérrez et al. 2006), and along with other better known euphausiid predators may significantly reduce the likelihood of E. pacifica females attaining sizes larger than $23 \mathrm{~mm}$.

We do not know why brood sizes of $>300$ egg female $^{-1}$ were not observed in the PS and TB populations, but perhaps the phytoplankton blooms in both regions were not of sufficient duration or magnitude to result in large euphausiid brood sizes. This supports the hypothesis that females in regions with short production seasons have smaller brood sizes. Another possibility, as suggested above, is that there was a relatively smaller sample size of females in the PS and TB regions than in the OC region, and the resultant data sets may not reflect the range of variability in brood size and fecundity for those locations.

Seasonal variations in water temperatures may also affect egg production. In TB, egg production occurs from February to May when the SST is $<12^{\circ} \mathrm{C}$ (Iguchi \& Ikeda 1999). SST increases significantly from 12 to $26^{\circ} \mathrm{C}$ between July and October, and a strong thermo- cline develops between 50 and $75 \mathrm{~m}$ depth. The magnitude of the nighttime vertical migration is reduced after May because of the temperature barrier $\left(>20^{\circ} \mathrm{C}\right)$ located at approximately $50 \mathrm{~m}$ depth, probably reducing feeding activity in the euphotic zone (Iguchi et al. 1993). Similarly, in the Oyashio Current, highest abundances of eggs in the water column were observed from April through June, when SST ranged from 5 to $12^{\circ} \mathrm{C}$; however, eggs were found only rarely in the Kuroshio, where temperatures were always $>15^{\circ} \mathrm{C}$ (Taki 2004). In PS, intense spawning usually occurs during April and May, which is earlier than on the OC, but continues at a low level throughout most of June (Ross et al. 1982). Since temperature in PS does not usually rise above $12^{\circ} \mathrm{C}$ in spring, the decrease in brood size after May is likely due to reduced phytoplankton concentrations, rather than temperature. In the OC region, spawning extends from March through October, with greatest intensity from July to September. The later and more intense spawning season here compared to the PS and TB regions is a result of the coastal upwelling. Upwelling benefits euphausiids in 2 ways: (1) by keeping the waters cool throughout the summer months (commonly $<14^{\circ} \mathrm{C}$ ) and (2) by promoting frequent phytoplankton blooms during the summer upwelling season (Feinberg \& Peterson 2003).

Brood size has been estimated for only a few other broadcast-spawning euphausiid species (Ross \& Quetin 2000). In the Benguela Current off South Africa, individual female Euphausia lucens Hansen (<18 mm female length) produced brood sizes up to 80 eggs female $^{-1}$ with relatively large eggs (550 to $600 \mu \mathrm{m}$ egg diameter) (Stuart \& Nicol 1986); thus, given the small body size compared to E. pacifica smaller brood sizes would be expected. Using counts of mature oöcytes in the ovary as an estimate of brood size for Euphausia hanseni, E. lucens and Nyctiphanes capensis, Stuart \& Nicol (1986) found that 'potential' brood sizes were quite small: between 19 and 138 eggs for females ranging in length from 8 to $27 \mathrm{~mm}$. Using the same approach of counting mature oocytes in ovaries, Brinton (1976) found a significant linear relationship between number of $E$. pacifica ripe oocytes and body length for individuals off southern California, but found an average of 150 ripe oocytes in 17 to $21 \mathrm{~mm}$ E. pacifica females and a maximum of 350 oocytes. He also found that the largest size class of females (21 mm) had a reduced number of oocytes, 140 per ovary, similar to our bell-shaped brood size distribution. Brinton's data on mean number of oocytes (on the order of 150 oocytes per ovary) are similar to our average E. pacifica brood size for females from the northern end of the California Current off Oregon state. However, his maximum number of oocytes (350) 
was far less than our direct measurements (800 eggs female $^{-1}$ ) from females maintained in the laboratory (L. R. Feinberg et al. unpubl.). These data suggest a common pattern among species from 2 upwelling systems related to embryo size and brood size: E. lucens and $E$. hanseni have larger diameter eggs than $E$. pacifica, resulting in reduced brood size. However, comparing the interspecific size continuum of $E$. lucens (small size), E. pacifica (intermediate) and E. superba (large size), there is a clear pattern of larger brood sizes in larger individuals.

Finally, we showed interspecific differences in egg diameter: on average, larger species have larger eggs (Fig. 4). The more interesting relationship in Fig. 4 is the large range in egg diameter among species of the same length. This suggests that some species with large eggs - for example, epipelagic oceanic species like Thysanoessa longipes, Euphausia similis, Thysanopoda tricuspidata, and Euphausia gibboides - have proportionally larger egg diameter but perhaps smaller brood sizes than Euphausia pacifica. Egg size is sometimes the only index that allows one to qualitatively evaluate the variations in maximum brood size among species (Timofeev \& Sklyar 2002). Because egg size information is available for only 23 of 57 broadcast-spawning euphausiid species, our analysis highlights the current gap in knowledge of egg biometry within the Order Euphausiacea.

\section{CONCLUSIONS}

When comparing brood sizes among euphausiids from different populations, length must be taken into account. Comparisons of brood size among populations can be confounded by the duration of the primary production season and potentially by temperature. If we are to determine whether Euphausia pacifica has differential reproductive investment under different environmental conditions, future studies devoted to estimating brood size are needed from other regions, particularly from those near the limits of the distribution range (i.e. East China Sea, Bering Sea and Baja California peninsula). Those inter-population differences cannot be addressed adequately without measurement of brood size, egg volume or diameter, interbrood period and spawning duration. Additional studies similar to ours need to be carried out for other euphausiid species in order to gain further insights into relationships between brood size and female length. If such studies are coupled with measurement of interbrood period, comparison of fecundity (determined from embryo energy content, interbrood period and spawning season) will be possible.

Acknowledgements. This research was supported by 2
Mamie Markham Research Awards from Oregon State University, Hatfield Marine Science Center (HMSC) during 2001-2002 and 2003-2004. Ship time and staff assistance were provided by the Office of Naval Research (National Ocean Partnership Program) in 1999-2000, US GLOBEC program in 2001 to 2004, jointly funded by the National Science Foundation, National Oceanic and Atmospheric Administration, and the NSF/CoOP COAST program (2001 and 2003). We thank C. B. Miller for his suggestions during this study, and the referees for valuable and critical comments. We thank N. Iguchi for allowing us to use his brood size Euphausia pacifica data set. We thank J. Keister, J. Lamb, A. Røstad, and M. Vance for their assistance with the collection of live euphausiids. J.G-G. was also supported by an SNI-II, COFAA-IPN, EDI-IPN fellowships, and a PhD CONACyT grant (122676) to study at Oregon State University (1998 to 2003). This is Contribution Number 291 from the US GLOBEC program.

\section{LITERATURE CITED}

Baker AdeC, Boden P, Brinton E (1990) A practical guide to the euphausiids of the world. Natural History Museum Publications, London

Batten S, Welch DW, Moore D (2005) Seasonal distribution of euphausiids on a transect from the Gulf of Alaska to the Bering Sea. In: Mechanisms of climate and human impacts on ecosystems in marginal seas and shelf regions. North Pacific Marine Science Organization (PICES) Fourteenth Annual Meeting. September 29-October 9, 2005, Vladivostok, abstract S2-2292, p 26

Bollens SM, Frost BW, Lin TS (1992) Recruitment, growth and diel vertical migration of Euphausia pacifica in a temperate fjord. Mar Biol 114:219-228

Brinton E (1962) The distribution of Pacific euphausiids. Bull Scripps Inst Oceanogr 8:51-270

Brinton E (1976) Population biology of Euphausia pacifica off southern California. Fish Bull 74:733-762

Brinton E, Ohman MD, Townsend AW, Knight MD, Bridgeman AL (2000) Euphausiids of the world ocean, Series: world biodiversity database CD-ROM series Windows version 1.0. Expert Center for Taxonomic Identification, Amsterdam, Netherlands. Springer Verlag, New York

Brodeur R, Yamamura O (eds) (2005) Micronekton of the North Pacific. PICES Sci Rep 30:1-115

Chae J, Hwang DJ, Kim YO, Kim D, Lee JH (2005) Euphausiid distribution near Uljin with special reference to its importance as a food source of demersal fish and impingement on the cooling water intakes of a power plant. In: Mechanisms of climate and human impacts on ecosystems in marginal seas and shelf regions. North Pacific Marine Science Organization (PICES) Fourteenth Annual Meeting. September 29-October 9, 2005, Vladivostok, abstract S2-2497, p 21

Dorman JG, Bollens SM, Slaughter AM (2005) Population biology of euphausiids off northern California and effects of short time-scale wind events on Euphausia pacifica. Mar Ecol Prog Ser 288:183-198

Feinberg LR, Peterson WT (2003) Variability in duration and intensity of euphausiid spawning off central Oregon, 1996-2001. Prog Oceanogr 57:363-379

Gilfillan ES (1972) Reactions of Euphausia pacifica Hansen (Crustacea) from oceanic, mixed oceanic-coastal and coastal waters of British Columbia to experimental changes in temperature and salinity. J Exp Mar Biol Ecol 10:29-40

Gómez-Gutiérrez J (2003) Comparative study of the population dynamic, secondary productivity, and reproductive 
ecology of the euphausiids Euphausia pacifica and Thysanoessa spinifera in the Oregon upwelling region. $\mathrm{PhD}$ thesis, Oregon State University, Corvallis, OR

Gómez-Gutiérrez J, Peterson WT, De-Robertis A, Brodeur R (2003) Mass mortality of krill caused by parasitoid ciliates. Science 301(5631):339

Gómez-Gutiérrez J, Peterson WT, Miller CB (2005) Crossshelf life-stage segregation and community structure of the euphausiids off central Oregon (1970-1972). In: Batchelder HP, Lessard E J, Strub PT, Weingartner TJ (eds) US GLOBEC biological and physical studies of plankton, fish and higher trophic level production, distribution, and variability in the Northeast Pacific. Deep-Sea Res II 52:289-315

Gómez-Gutiérrez J, Peterson WT, Morado FJ (2006) Discovery of a ciliate parasitoid of euphausiids off Oregon, USA: Collinia oregonensis n. sp. (Apostomatida: Colliniidae). Dis Aquat Org 71:33-49

Iguchi N, Ikeda T (1994) Experimental study on brood size, egg hatchability and early development time of the euphausiid Euphausia pacifica from Toyama Bay, Southern Japan Sea. Bull Jpn Sea Nat Fish Res Inst 44:49-57

Iguchi N, Ikeda T (1999) Production, metabolism and P:B ratio of Euphausia pacifica (Crustacea: Euphausiacea) in Toyama Bay, southern Japan Sea. Plankton Biol Ecol 46: 68-74

Iguchi N, Ikeda T, Imamura A (1993) Growth and life cycle of a euphausiid crustacean (Euphausia pacifica Hansen) in Toyama Bay, Southern Japan Sea. Bull Jpn Sea Natl Fish Res Inst 43:69-81

Johnson MW (1956) The plankton of Beaufort and Chukchi Sea areas and its relation to the hydrography. Arctic Inst N Am, Tech Pap 1:1-32

Lamb J, Peterson WT (2005) Ecological zonation of zooplankton in the COAST study region off central Oregon in June and August 2001 with consideration of retention mechanisms. J Geophys Res C: Oceans 110(10):1-14

Mauchline J (1988) Egg and brood sizes of oceanic pelagic crustaceans. Mar Ecol Prog Ser 43:251-258

Peterson WT, Gómez-Gutiérrez J, Morgan C (2002) Crossshelf variation in calanoid copepod production during summer 1996 off the Oregon coast, USA. Mar Biol 141: 353-365

Editorial responsibility: Otto Kinne (Editor-in-Chief), Oldendorf/Luhe, Germany
Ponomareva LA (1963) Euphausiids of the North Pacific, their distribution and ecology. Dokl Akad Nauk SSSR, Israel program for scientific translation, Jerusalem

Ramsey FL, Schafer DW (1996) The statistical sleuth: a course in methods of data analysis. Duxbury Press, Belmont, CA

Reagan LR (1968) Euphausia pacifica and other euphausiids in coastal waters of British Columbia: relationships to temperature, salinity and other properties in the field and laboratory. PhD thesis, University of British Columbia, Vancouver

Ross RM, Quetin LB (2000) Reproduction in Euphausiacea. In: Everson I (ed) Krill biology, ecology and fisheries. Fisheries and aquatic resources series. Blackwell Science, Cambridge, p 150-181

Ross RM, Daly KL, English TS (1982) Reproductive cycle and fecundity of Euphausia pacifica in Puget Sound, Washington. Limnol Oceanogr 27:304-314

Smiles MC, Pearcy WG (1971) Size structure and growth rate of Euphausia pacifica off the Oregon coast. Fish Bull 69: 79-86

Stuart V, Nicol S (1986) The reproductive potential ofthree euphausiid species from the southern Benguela region. J Exp Mar Biol Ecol 103:267-274

Taki K (2004) Distribution and life history of Euphausia pacifica off northeastern Japan. Fish Oceanogr 13:34-43

Timofeev SF, Sklyar VV (2002) Egg size in the euphausiid Thysanoessa raschii (M. Sars, 1864) (Euphausiacea) in the Barents Sea. Crustaceana 74:1201-1211

Wang J, Sun Y, Liu C, Chen X, Xu R (2005) Quantitative distribution of euphausiids in the East China Sea and the Yangtze Estuary in relation to the environmental conditions. In: Mechanisms of climate and human impacts on ecosystems in marginal seas and shelf regions. North Pacific Marine Science Organization (PICES) Fourteenth Annual Meeting. September 29-October 9, 2005, Vladivostok, abstract S2-2412, p 25

$\mathrm{Xu}$ ZL, Chen YQ (2005) Study on the dominant species of euphausiids in the East China Sea and their ecological adaptability. In: Mechanisms of climate and human impacts on ecosystems in marginal seas and shelf regions. North Pacific Marine Science Organization (PICES) Fourteenth Annual Meeting.September 29-October 9, 2005, Vladivostok, abstract S2-2533, p 27

Submitted: September 2, 2005; Accepted: April 10, 2006 Proofs received from author(s): September 16, 2006 